\title{
Induction of Tumors in Anthurium andraeanum by Agrobactemium tumefaciens
}

\author{
A.R. Kuehnle' and N. Sugii ${ }^{2}$ \\ Department of Horticulture, University of Hawaii, Honolulu, HI 96822
}

Additional index words. transformation, ornamental, tropical monocot, T-DNA, nopaline

Abstract. A method was devised for infecting Anthurium andraeanum Linden ex André, an economically important ornamental monocot, with Agrobacterium tumefaciens. Tumors were obtained on plant stems 7 to 10 weeks after inoculation with oncogenic $A$. tumefaciens strains $\mathrm{C} 58$ and A281 cultured previously in an induction medium containing $200 \mu \mathrm{M}$ acetosyringone at $\mathrm{pH}$ 5.5. A higher percentage of tumors were formed in vitro on etiolated internodes $(32 \%)$ than on green leaf $(2 \%)$ or petiole explants $(3 \%)$ 4 weeks after inoculation with induced C58. All explants treated with nontumorigenic $A$. radiobacter or with induction medium alone failed to produce tumors. Chromatograms showed an accumulation of nopaline in internode explant tumors induced with C58. DNA amplification and hybridization studies showed that the DNA from these tumors, but not from noninoculated anthurium tissue, contained sequences homologous to the nopaline synthase gene of $A$. tumefaciens T-DNA. Chemical names used 3,5dimethoxy 4-hydroxyacetophenone (acetosyringone).

Improvement of anthuriums, an important flower crop in Hawaii and Holland, through hybridization and selection is a long-term effort requiring 2 to 3 years for plants to mature and produce seed. A reliable gene transfer system for anthuriums could be convenient to breeders interested in improving flower color and bacterial disease resistance.

The soil bacterium Agrobacterium tumefaciens can naturally transfer a segment of plasmid DNA, T-DNA, into the genome of a wounded plant (Chilton et al., 1977) and is well established as a vector for plant genetic transformation. Expression of some wild-type T-DNA genes can cause overproduction of auxins and cytokinins in plant cells, leading to the growth of tumors (Braun, 1958; Garfinkel et al., 1981; Ooms et al., 1981). Other T-DNA genes are responsible for the synthesis of opines, such as nopaline, in infected plant cells (Bomhoff et al., 1976). The vir gene region of plasmid DNA affects T-DNA transfer and integration; while it is required for plant infection, it is not integrated into the host genome (Horsch et al., 1986). Expression of vir genes can be induced by various phenolic compounds, including acetosyringone (Bolton et al., 1986; Stachel et al., 1985).

Agrobacterium-mediated transformation has been most useful with dicotyledonous plants

Received for publication 20 Nov. 1990. Journal Series no. 3549 of the Hawaii Institute of Tropical Agriculture and Human Resources. Research supported in part by the State of Hawaii Governor's Agricultural Coordinating Committee and the Hawaiian Anthurium Industry Association. We thank A. Alvarez for her assistance. The coat of publishing this paper was defrayed in part by the payment of page charges. Under postal regulations, this paper therefore must be hereby marked $a d$ vertisement solely to indicate this fact.

'Assistant Horticulturist.

${ }^{2}$ Research Associate. that, upon wounding, can induce expression of the vir genes. Recent studies have supported infection by Agrobacterium of monocots found in the Liliaceae, Iridaceae, Gramineae, and Dioscoreaceae (Bytebier et al., 1987; Graves and Goldman, 1986, 1987; Grimsley et al., 1987; Hemalsteens et al., 1984; Raineri et al., 1990; Schafer et al., 1987; Woolston et al., 1988). Of the 13 genera examined within the monocotyledonous family Araceae, only Calla and Philodendron were reported to be susceptible to infection by $A$. tumefaciens strain B6 (de Cleene, 1985); however, anthurium was not susceptible when inoculated with uninduced A. tumefaciens strains C58, 920, A4, CG935, 937, K27, CG108, and 49 (Kuehnle, unpublished data).

In this study, we examined the susceptibility of Anthurium andraeanum plants and explants to infection by induced oncogenic strains of Agrobacterium tumefaciens.

Agrobacterium biovar 1 strains, from the collections of L. Moore (Oregon State Univ.,

Table 1. Response of Anthurium andraeanum selection UH965 explants to Agrobacterium tumefaciens strain C58 induced with acetosyrincone.

\begin{tabular}{lrc}
\hline \hline & \multicolumn{2}{c}{ No. explants } \\
\cline { 2 - 3 } $\begin{array}{l}\text { Plant part } \\
\text { and treatment }\end{array}$ & \multicolumn{2}{c}{$\begin{array}{c}\text { With } \\
\text { tumor (\%) }\end{array}$} \\
\hline Petiole & & \\
$\quad$ Control (YEP) & \\
A. tumefaciens C58 & 40 & $0(0)$ \\
Leaf & 60 & $2(3)$ \\
$\quad$ Control (YEP) & & \\
$\quad$ A. tumefaciens C58 & 40 & $0(0)$ \\
Etiolated internode & 60 & $1(2)$ \\
$\quad$ Control (YEP) & & \\
A. radiobacter control & 94 & $0(0)$ \\
A. tumefaciens C58 & 187 & $60(32)$ \\
\hline
\end{tabular}

${ }^{2}$ Induction medium containing $200 \mu \mathrm{M}$ acetosyringone.
Corvallis) and A. Alvarez (Univ. of Hawaii, Honolulu), were grown for 24 to $36 \mathrm{~h}$ at 50 $\mathrm{rpm}, 28 \mathrm{C}$, in liquid YEP medium consisting of $1 \%$ Bactopeptone, $1 \%$ Bacto-yeast extract, and $0.5 \% \mathrm{NaCl}$ (An et al., 1988) with $200 \mu \mathrm{M}$ acetosyringone (Aldrich Chemical, Milwaukee) at $\mathrm{pH} 5.5$ (YEP induction medium). Two common tumor-inducing strains with a wide host range were tested: C58 harboring the nopaline plasmid pTi-C58 and A281 combining the chromosomal background of C58 with the succinamopine plasmid pTi-Bo542. To ensure that the C58 and A281 cultures were virulent at the time of experimentation, inoculations were performed on young plants of Turkish tobacco (Nicotiana tabacum L.) as positive controls.

Anthurium seedlings from four genetically diverse crosses, referred to by cross numbers $926,932,935$, and 976 hereafter, were grown in flats in a glasshouse with $80 \%$ shade and $\approx 29 \mathrm{C}$ day/23C night with a natural photoperiod. Stems of 8- to 12-month-old juvenile plants of all four crosses were punctured with a sterile dissecting needle dipped in heavy aqueous suspensions of strain C58. Other seedlings of crosses 926 and 976 were treated with strain A281. Stems wounded with a dissecting needle dipped in YEP induction medium served as controls. Wound sites were covered with petroleum jelly to maintain a humid environment favorable for bacterial proliferation and infection. The tumorigenic response was evaluated after 7 to 10 weeks by use of a 0 to 5 scale, where $0=$ a smooth swelling of $<1 \mathrm{~mm}$ in diameter at the wound site and ratings of 1 to $5=$ rough, raised growths $\geq 1$ to $5 \mathrm{~mm}$ in diameter, respectively. Sample sizes were $n=13$ controls and 14 inoculations for 935 and $932 ; n=9$ controls and 10 inoculations each for C58and A281-exposed 926; and $\mathrm{n}=27$ controls

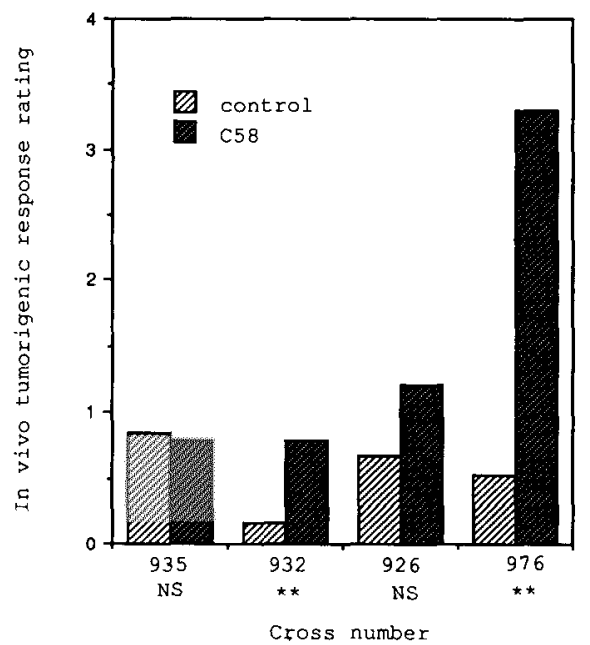

Fig. 1. Mean response rating of seedlings from four anthurium crosses 7 to 10 weeks after inoculation with Agrobacterium tumefaciens strain C58 induced with acetosyringone. Controls were treated with YEP induction medium lacking bacteria. Ratings reflect tumor size and appearance, with large raised tumors receiving higher ratings than small, smooth tumors. Means were compared using the Mann-Whitney test; (NS) nonsignificant, (**) significant at $P<0.001$. 

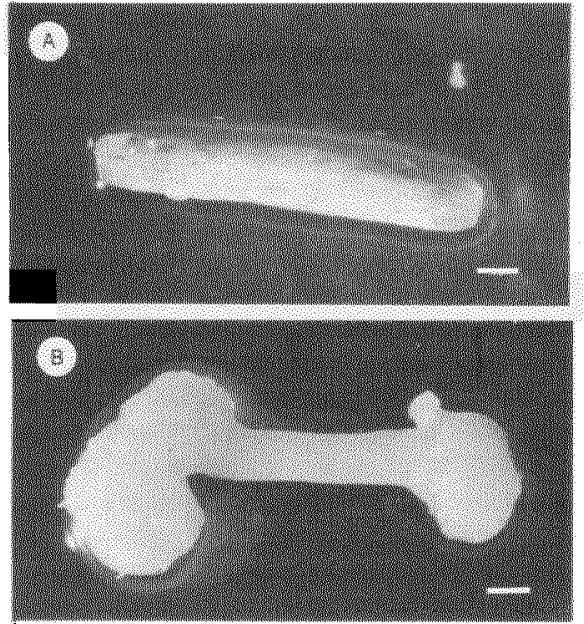

Fig. 2. Tumor growth on etiolated internode segments of anthurium selection UH965 7 weeks after inoculation with YEP induction medium lacking bacteria (A) or with Agrobacterium tumefaciens strain C58 induced with acetosyringone (B). Scale bar $=1 \mathrm{~mm}$.

and 23 and 27 inoculations for C58- and A281-exposed 976, respectively. As a negative control, inoculations were also made with nonpathogenic $A$. radiobacter using cross $926(\mathrm{n}=10)$. Data were analyzed using the nonparametric Mann-Whitney and KruskalWallis tests (Sokal and Rohlf, 1981).

Micropropagated plantlets of the Univ. of Hawaii selection UH965, grown in vitro either under a 16-h light/8-h dark photoperiod with $54 \mu \mathrm{mol} \cdot \mathrm{m}^{-2} \cdot \mathrm{s}^{-1}$ photosynthetically active radiation at $25 \pm 2 \mathrm{C}$ or in the dark at $21 \mathrm{C}$, provided $0.5-\mathrm{cm}^{2}$ leaf pieces and $1-\mathrm{cm}$-long petiole or etiolated internode explants. UH965 plantlets, established in vitro via axillary bud culture (Kunisaki, 1980), were subculture for 1 year at regular intervals on a modified MS medium (Murashige and Skoog, 1962) composed of half-strength MS macronutrients, full-strength MS micronutrients, MS vitamins with thiamine $\mathrm{HCl}$ increased to 0.4 mg.liter ${ }^{-1}, 25 \mathrm{mg}$ NaFeEDTA/liter, $100 \mathrm{mg}$ myo-inositol/liter, 2\% sucrose, $2.2 \mu \mathrm{M} N$ (phenylmethyl)-lH-punne-6-amine (BA), and solidified with $0.7 \%$ Bacto-agar (half-strength MS medium).

Explants were dipped in aqueous bacterial cultures, blotted, and then cocultivated with bacteria on 7-cm-diameter cellulose filter papers supported by 3-day-old subcultures of Su tobacco nurse callus (gift of E.D. Earle, Cornell Univ., Ithaca, N. Y.) grown on MS medium containing $1 \mathrm{mg}$ (2,4-dichlorophenoxy)acetic acid (2,4-D)/liter. After 3 days of culture in the dark at 25 to $28 \mathrm{C}$, explants were blotted and transferred from the nurse cultures onto half-strength MS medium containing no growth regulators and $500 \mathrm{mg}$ carbenicillin/liter. Control explants were treated similarly using YEP induction medium either lacking bacteria or containing A. radiobacter. Cultures were grown in the dark at $21 \mathrm{C}$ for 4 weeks and then evaluated. The number of explants with at least one tumor visible without magnification was recorded. Noncallus swellings occurred occasionally at the

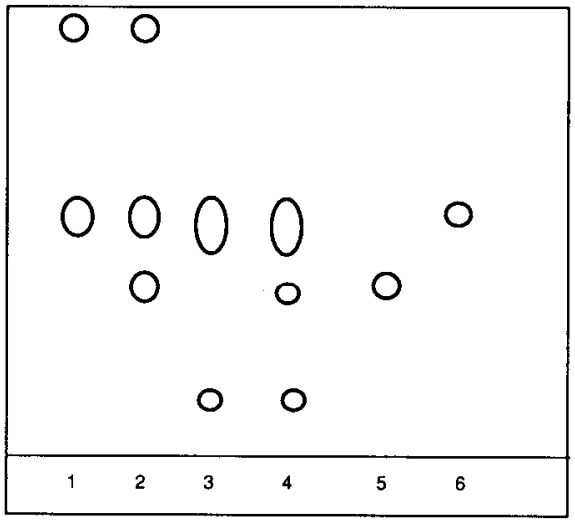

Fig. 3. Diagram of a thin-layer chromatogram showing nopaline and other guanidine compounds accumulated in extracts of tumors from etiolated internodes of anthurium selection UH965 infected by acetosyringone-induced Agrobacterium tumefaciens strain C58. Turkish tobacco leaf extracts served as controls. Lane 1 , uninfected tobacco, $R f=0.41,0.73$; lane 2, tobacco tumor, $R f=0.25,0.41,0.73$; lane 3 , uninfected anthurium, $R f=0.08,0.40$ lane 4, anthurium tumor, $R f=0.08,0.25,0.40$; lane 5, nopaline standard, $R f=0.26$; and lane 6 , arginine standard, $R f=0.41$.

wounded edges of explants and were judged not to be tumors. Leaf explants of Turkish tobacco inoculated at the same time as anthurium explants served as positive controls for $\mathrm{C} 58$ virulence.

Nopaline accumulation was examined in tissues treated with C58 and in control tissues; free-living C58 served as an additional control. Extracts obtained by the procedure of Hemalsteens et al. (1984) were concentrated by freeze-drying and resuspended in small volumes of sterile water. Nopaline was detected by the procedure of Herrera-Estrella et al. (1988), modified for ascending thinlayer chromatography by using glass plates precoated with $250-\mu \mathrm{m}$-thick MN300 cellulose (Analtech, Newark, Del.). Chromatograms were run for $2 \mathrm{~h}$ before developmentand observed under long-wave ultraviolet illumination. The solvent front was marked, the outlines of any visible spots traced, and Rf values calculated.

DNA from anthurium and tobacco tumors and control tissues was extracted for polymerase chain reaction (PCR) and Southern blot (Southern, 1975) analyses using the procedure of Dellaporta et al. (1983), modified by precipitation of the final DNA pellet in $350 \mu \mathrm{l} 7.5 \mathrm{~m}$ ammonium acetate, $75 \mu \mathrm{l} 3 \mathrm{~m}$ sodium acetate, and $500 \mu \mathrm{l}$ isopropanol with microcentrifugation for $10 \mathrm{~min}$.

A 1.2-kb nopaline synthase (nos) gene fragment from the plasmid pMON530 in Escherichia coli strain NM294 was used as the probe for transformed tissue DNA. Plasmid DNA was isolated from $E$. coli using an alkaline lysis method (Liszewski et al., 1989; Sambrook et al., 1989). PCR amplification of the nos fragment for probe preparation or for plant DNA analysis was carried out according to Sambrook et al. (1989) using two $21 \mathrm{bp}$ primers whose sequences were derived from the first and last seven codons of the nos coding sequence of the nopaline plasmid pTi-T37 (Depicker et al., 1982). The oligonucleotide primers, GCAATTACCTTATCCGCAACT and GACCATCTCGTCCTTATTGAA (5' to 3 '), were produced at the Univ. of Hawaii Biotechnology Instrumentation Facility. PCR amplification involved three temperature/time profiles for a total of 30 cycles; a first cycle of $94 \mathrm{C} / 4$ rein, $60 \mathrm{C} / 2 \mathrm{rein}, 72 \mathrm{C} / 3 \mathrm{~min}$ followed by $94 \mathrm{C} /$ $1 \mathrm{rein}, 60 \mathrm{C} / 2 \mathrm{rein}, 72 \mathrm{C} / 3$ rein, with a final cycle of $94 \mathrm{C} / 1 \mathrm{rein}, 60 \mathrm{C} / 2$ rein, $72 \mathrm{C} / 11 \mathrm{~min}$. An aliquot of $2 \mu \mathrm{g}$ plant DNA from tumor or control tissue was used for nos amplification. The PCR-amplified DNA fragments were purified and quantified according to Sambrook et al. (1989).

Probe DNA was prepared using randomprimed incorporation of deoxyuridine triphosphate linked to digoxigenin according to directions for the Genius Nonradioactive DNA Labeling and Detection Kit (Boehringer Mannheim Biochemical, Indianapolis).

Amplified DNA was electrophoresed in 50 $\mathrm{ml}$ of $0.8 \%$ agarose gel (Fisher Biotech Low EEO Agarose; Fisher Scientific, Fair Lawn, N. J.) using $0.5 \times$ TBE buffer containing $44.5 \mathrm{~mm}$ Tris base, $44.5 \mathrm{~mm}$ boric acid, and 1 mM EDTA. DNA was transferred overnight from the gel onto a Zetabind nylon membrane according to the manufacturer's directions for capillary transfer (CUNO, Meriden, Corm.). The membrane was airdried for $2 \mathrm{~h}$ at 28C. Prehybridization and hybridization of the membrane was carried out overnight at $68 \mathrm{C}$ in a sealed, plastic hybridization bag following instructions for the Genius Kit. About 100 ng of digoxigeninlabeled nos probe, freshly denatured at 94C for $10 \mathrm{~min}$ followed by an ethanol/ice bath, was used in $2.5 \mathrm{ml}$ of hybridization solution. Immunological color detection of probe DNA hybridized to PCR-amplified products was as described for the Genius Kit. In this procedure, the membrane was blocked, reacted with antidigoxigenin alkaline phosphatase conjugate, washed, then reacted with freshly prepared color solution containing 5-bromo4-chloro-3-indolyl phosphate and nitroblue tetrazolium salt. The reaction was stopped after $1.5 \mathrm{~h}$, and the wet membrane was photographed.

A second membrane was spotted with denatured genomic DNA from anthurium tumors or control tissues $(30 \mu \mathrm{g})$ and pMON530 plasmid DNA $(0.01 \mu \mathrm{g})$ using a standard dot blot procedure (Davis et al., 1986). After spotting, the membrane was air-dried for 2 h. Southern hybridization was done using digoxigenin-labeled nos probe as described above. Immunochemiluminescent detection of hybridized probe using Lumi-Phos 530 (Boehringer Mannheim Biochemical) was done following manufacturer's directions. Using this method, the membrane that had been reacted with antidigoxigenin alkaline phosphatase conjugate was dipped into LumiPhos 530 substrate solution, incubated in a sealed hybridization bag for $30 \mathrm{~min}$ at $37 \mathrm{C}$, and exposed to XAR-5 film (Kodak Co., Rochester, N. Y.) for 7 to $10 \mathrm{~min}$. The film was developed for 20 to $30 \mathrm{sec}$, fixed ac- 


\section{. M1234}

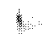

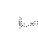

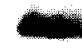

Fig. 4. Polymerase chain reaction analysis of DNA from anthurium selection UH965 tumor tissue. A probe specific for nos from the TDNA region of the Ti plasmid hybridizes to a $1.2-\mathrm{kb}$ fragment amplified using primers for $\mathrm{pTi}-$ T37 nos. Lane 1, Turkish tobacco leaf tissue treated with induced Agrobactetium turrrefaciens C58 (positive control); lane 2, anthurium etiolated internode tissue treated with induced A. tumefaciens C58; lane 3, uninfected UH965 etiolated internode tissue; lane 4, pMON530 carrying pTi-T37 nos (positive control). Lane $M$ is Hind III-digested Lambda DNA.

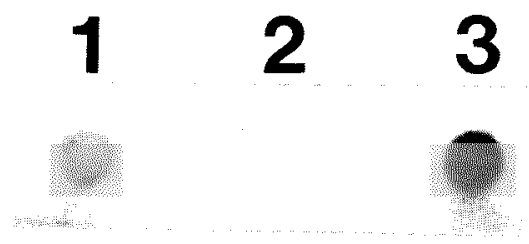

Fig. 5. Dot-blot hybridization of genomic DNA from anthurium selection UH965 tumor tissue to a probe specific for nos from the T-DNA region of the $\mathrm{Ti}$ plasmid. Dot 1 , anthurium etiolated internode tissue treated with induced Agrobacterium tumefaciens C58; dot 2, uninfected UH965 etiolated internode tissue; and dot 3 , pMON530 carrying pTi-T37 nos (positive control).

cording to Kodak X-ray film processing instructions, and photographed.

Small tumors resembling raised scars were produced on plants treated with induced Agrobacterium and were significantly larger $(P<0.001)$ in two out of the four anthurium crosses tested than those on control plants inoculated with YEP induction medium (Fig. 1). Variability among crosses was highly significant $(P=0.0001)$, indicating that tumor formation by induced C58 is strongly affected by the plant genetic background. In addition, the response of cross 926 to induced C58 was significantly greater than that produced by $A$. radiobacter $(P=0.02)$, with a mean response rating of 1.2 compared to 0.4 . These results indicate that tumor growth in anthurium is not a general reaction to Agrobacterium or to the wounding itself.

Among all the crosses, plants of 976 treated with $A$. tumefaciens produced the largest tumors. Tumorigenesis in C58- and A281treated plants of cross 976 was highly significant compared to the response of controls, with mean response ratings of 3.3 and 2.6 , respectively $(P=0.0001)$. Tumor growth differed significantly between C58 and A281 $(P=0.05)$, with C58 producing the largest growths. In contrast, the response of cross 926 to infection by strain A281 did not differ significantly from the control response $(P=0.67)$. This result supports the observation that the pathogenicity of different $A$. tumefaciens strains varies with the host genotype (Anderson and Moore, 1979).

Agrobactetium tumefaciens C58 induced clearly visible tumors on etiolated internode explants (32\%) and about one-tenth as many or fewer on green leaf and petiole explants (Table 1, Fig. 2). Tumors were firm and pale yellow, could be maintained on medium with no growth regulators, and resembled the callus that develops on explants during the early stages of micropropagation on auxin- and cytokinin-rich medium (Pierik, 1976). Leaf and petiole explants treated with A. radiobacter or with YEP induction medium failed to produce tumors (Table 1). A few etiolated explants treated with $\boldsymbol{A}$. radiobacter $(3 \%)$ or YEP induction medium (3\%) produced swellings that were initially difficult to distinguish from callus-type tumors but that did not continue to grow. Chromatograms showed an accumulation of nopaline in C58-exposed anthurium internode and tobacco leaf tumors (positive control), but not in noninoculated tissues (Fig. 3); C58 extract did not show nopaline accumulation.

Southern analysis of PCR-amplified DNA showed a $1.2-\mathrm{kb}$ band present in C58-induced anthurium tumors but absent in uninfected control tissue exposed to YEP induction medium (Fig. 4). The positive controls, C58-exposed tobacco leaf tumor and pMON530 plasmid DNAs, also showed a 1.2-kb amplified band with homology to the nos probe. From dot-blot hybridization (Fig. 5 ), it is evident that the nos gene is absent in normal anthurium DNA but is present in tumorous anthuriurn DNA. These data, taken together with the whole-plant observations and the biochemical evidence, demonstrate that the tumorous phenotype seen on C58treated anthurium explants is due to the presence of T-DNA transferred from A. tumefaciens.

These results show that infection of etiolated tissue by acetosyringone-induced $A$. tumefaciens strain C58 is a reliable method for the production of tumors carrying transgenes in anthurium. This work expands the host range of A. tumefaciens to include the monocot family Araceae and emphasizes the importance of explant, genotype, and bacterial strain selection in development of such transformation systems. As methods for callus induction and plant regeneration have been developed for many anthurium cultivars (Geier, 1990; Kuehnle and Sugii, 1991) and as transgenic anthurium shoots with a normal vegetative appearance have been recovered from some C58-induced tumors (unpublished data), this work represents a potentially significant advance in the tools for breeding anthurium. Further studies with nontumorigenic C58 strains carrying selectable marker genes in the T-DNA could demonstrate that horticulturally desirable traits can be introduced and expressed in anthurium using A. tumefaciens as a vector.

\section{Literature Cited}

An, G., P.R. Ebert, A. Mitra, and S.B. Ha. 1988. Binary vectors, p. 1-19. In: S.B. Gelvin and R.A. Schilperoort (eds.). Plant Mol. Biol. Manual A3. Kluwer Academic, Dordrecht, Netherlands..

Anderson, A.R. and L.W. Moore. 1979. Host specificity in the genus Agrobacterium. Phytopathology 69:320-323.

Bolton, G. W., M.P. Gordon, and E.W. Neater. 1986. Plant phenolic compounds induce expression of the Agrobacterium tumefaciens loci required for virulence. Science 232:983-985.

Bomhoff, G., P.M. Klapwijk, H.C.M. Kester, R.A. Schilperoort, J.P. Hemalsteens, and J. Schell. 1976. Octopine and nopaline synthesis and breakdown genetically controlled by a plasmid of Agrobacterium tumefaciens. Mol. Gen. Genet. 145:177-181.

Braun, A.C. 1958. A physiological basis for autonomous growth of crown gall tumor cell. Proc. Natl. Acad. Sci. (USA) 44:344-349.

Bytebier, B., F. Deboeck, H. de Greve, M. Van Montagu, and J.P. Hernalsteens. 1987. T-DNA organization in tumor cultures and transgenic plants of the monocotyledon Asparagus officinalis. Proc. Natl. Acad. Sci. (USA) 84:53455349.

Chilton, M.-D, M.H. Drummond, D.J. Merle, D. Sciaky, A.L. Montoya, M.P. Gordon, and E.W. Nester. 1977. Stable incorporation of plasmid DNA into higher plants: The molecular basis of crown gall tumorigenesis. Cell 11:263-271.

Davis, L., M. Dibner, and J. Battery. 1986. Basic methods in molecular biology. Elsevier, New York.

De Cleene, M. 1985. The susceptibility of monocotyledons to Agrobacterium tumefaciens. Phytopathol. Z. 113:81-89.

Dellaporta, S. L., J. Wood, and J.B. Hicks. 1983. A plant DNA minipreparation: Version II. Plant Mol. Biol. Rpt. 1:19-21.

Depicker, A., S. Stachel, P. Dhaese, P. Zambryski, and H.M. Goodman. 1982. Nopaline synthase: Transcript mapping and DNA sequence. J. Mol. Applied Genet. 1:561-573.

Garfinkel, D.J., R.B. Simpson, L.W. Ream, F.F. White, A.P. Gordon, and E.W. Nester. 1981. Genetic analysis of crown gall: Fine structure map of the T-DNA by site-directed mutagenesis. Cell 27:143-153.

Geier, T. 1990. Anthurium, p. 228-252. In: P.V. Ammirato, D.A. Evans, W.R. Sharp, and Y.P.S. Bajaj (eds.). Handbook of plant cell culture. vol. 5. McGraw-Hill, New York.

Graves, A.C. and S.L. Goldman. 1986. The transformation of Zea mays seedlings with Agrobacterium tumefaciens Detection of T-DNA specific enzyme activities. Plant Mol. Biol. 7:4350.

Graves, A.C. and S.L. Goldman. 1987. Agrobacterium tumefaciens-mediated transformation of the monocot genus Gladiolus: Detection of the 
Grimsley, N., T. Hohn, J.W. Davies, and B. Hohn. 1987. Agrobactetium-mediated delivery of infectious maize streak virus into maize plants. Nature 325:177-179.

Hernalsteens, J.-P., L. Thia-Toong, J. Schell, and M. Van Montagu. 1984. An Agrobacteriumtransformed cell culture from the monocot $A s$ paragus officinalis. EMBO J. 3:3039-3041.

Herrera-Estrella, L., T.H. Teeri, and J. Simpson. 1988. Use of reporter genes to study gene expression in plant cell, p. 1-22. In: S.B. Gelvin and R.A. Schilperoort (eds.). Plant Mol. Biol. Manual B1. Kluwer Academic, Dordrecht, Netherlands.

Horsch, R. B., H.J. Klee, S. Stachel, S.C. Winans, E.W. Nester, S.G. Rogera, and R.T. Fraley. 1986. Analysis of Agrobacterium tumefaciens virulence mutants in leaf discs. Proc. Natl. Acad. Sci. (USA) 83:2571-2575.

Kuehnle, A.R. and N. Sugii. 1991. Callus induction and plantlet regeneration in tissue cultures of Hawaiian anthuriums. HortScience 26:919 921.

Kunisaki, J.T. 1980. In vitro propagation of $A n$ thurium andraeanum Lind. HortSciencc 15:508509.

Liszewskl, M. K., V. Kumar, and J.P. Atkinson. 1989. "Midi-prep" isolation of plasmid DNA in less than two hours for sequencing, subcloning, and hybridizations. BioTechniques 7:1079 1081

Murashige, T. and F. Skoog. 1962. A revised medium for rapid growth and bioassays with tobacco tissue cultures. Physiol. Plant. 15:473 497.

Ooms, G., P.J.J. Hooykaas, G. Moolenaar, and R.A. Schilperoort. 1981. Crown gall plant tumors of abnormal morphology induced by Agrobacterium tamefaciens carrying mutated octopine Ti plasmids; Analysis of T-DNA functions. Gene 14:33-50.

Pierik, R.L.M. 1976. Anthurium andraeanum plantlets produced from callus tissues cultivated in vitro. Physiol. Plant. 37:80-82.

Rairreri, D. M., P. Bottino, M.P. Gordon, and E.W. Nester. 1990. Agrobacterium-mediated transformation of rice (Oryza sativa L.). Bio/Technology 8:33-38.

Sambrook, J., E.F. Fritsch, and T. Maniatis. 1989 Molecular cloning: A laboratory manual. 2nd ed. Cold Spring Harbor Laboratory Press, New York.

Schafer, W., A. Görz, and G. Kahl. 1987. TDNA integration and expression in a monocot crop after induction of Agrobacterium. Nature (London) 327:529-532.

Sokal, R.R. and F.J. Rohlf. 1981. Biometry The principles and practice of statistic in biological research. W.H. Freeman and Co., San Francisco.

Southern, E.M. 1975. Detection of specific sequences among DNA fragments separated by gel electrophoresis. J. Mol. Biol. 98:503-518.

Stachel, S. E., E. Messens, M. Van Montagu, and P. Zambryski. 1985. Identification of the signal molecules produced by wounded plant cells that activate T-DNA transfer in Agrobacterium tumefaciens. Nature (London) 318:624-629.

Woolston, C.J., R. Barker, H. Gunn, M.L Boulton, and P.M. Mullineaux. 1988. Agroinfection and nucleotide sequence of cloned wheat dwarf virus DNA. Plant Mol. Biol. 11:35-43. 